International Journal of Applied Research 2021; 7(3): 136-137

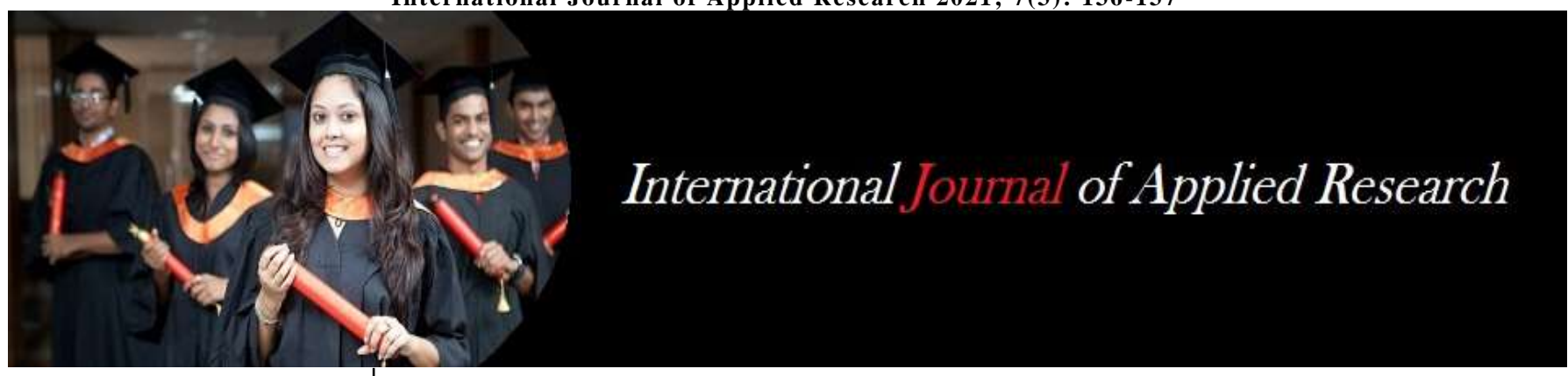

ISSN Print: 2394-7500 ISSN Online: 2394-5869 Impact Factor: 8.4

IJAR 2021; 7(3): 136-137 www.allresearchjournal.com

Received: 06-01-2021 Accepted: 09-02-2021

असरा बीबी सिद्दीकी असिस्टेंट प्रोफेसर, (समाजशास्त्र) करामत हुसैन मुस्लिम गर्ल्स पी०जी०कालेज, निशातगंज, लखनऊ, उत्तर प्रदेश, भारत।
Corresponding Author: असरा बीबी सिद्दीकी असिस्टेंट प्रोफेसर, (समाजशास्त्र) करामत हुसैन मुस्लिम गर्ल्स पी०जी०कालेज, निशातगंज, लखनऊ, उत्तर प्रदेश, भारत।

\section{स्वस्थ समाजीकरण के सशक्त अभिकरण के रूप मे परिवार की भूमिका}

\section{असरा बीबी सिद्दीकी}

DOI: https://doi.org/10.22271/allresearch.2021.v7.i3c.8382

\section{प्रस्तावना:}

स्वस्थ समाजीकरण के अभिकरण के रूप मे परिवार की भमिका अत्यन्त विशिश्ट होती है। परिवार चाहे विस्तृत हो, संयुक्त हो, एकाकी हो या मिश्रित हो, व्यक्ति के जीवन में महत्वपूर्ण स्थान रखता है। परिवार वह स्थान है जहॉ व्यक्ति मानवतावादी गुणों को सीखता है इसलिये परिवार को बालक की प्राथमिक पाठशाला कहा जाता है जहॉ बालक प्रेम, दया, सहानुभूति, सामन्जस्य, अनुशासन, न्याय, संस्कार, आदर्श, मूल्य, नियंत्रण, सहयोग आदि गुणों सीखता है।

परिवार प्राथमिक समूह के अन्तर्गत आता है। परिवार में बालक के व्यक्तित्व का परिपूर्ण विकास होता है। "परिवार समाज की प्राथमिक एंव मौलिक इकाई है और उस रूप में अनेक कार्यो को करना पड़ता है। म्सउमत का विचार है कि आज का मानव कितने ही अनोखे अविश्कार कर रहा है फिर भी परिवार के अतिरिक्त ऐसे किसी दूसरे योग्य संगठन का अविश्कार नहीं कर पाया है जिसपर परिवार के आधारभूत कार्यों को निर्भर व निश्चिंत होकर सौपा जाये।"1 परिवार बालक का सफल समाजीकरण करने में अपनी महत्वपूर्ण भूमिका निभाता है। समाजीकरण के द्वारा बालक में समाज में जीने की क्षमता एंव योग्यता का विकास होता है। परिवार वह स्थान है जहॉ बालक चलना सीखता है, बोलना सीखता है, बड़ों का आदर, छोटों का सम्मान, बहन भाई से प्रेम, उत्तरदायित्व की भावना इत्यादि को सीखता है तथा उसमें क्षमाशीलता की भावना का विकास होता है।

"मानव समाज के सम्पूर्ण इतिहास में परिवार का महत्व सबसे अधिक रहा है। व्यक्ति परिवार मे जन्म लेता है तथा परिवार में ही उन नियमों और व्यवहारों को सीखता है जो उसे सच्चे अर्थों में एक सामाजिक प्राणी बनाते हैं। कोई समाज चाहे परम्परागत हो अथवा आधुनिक, ग्रामीण हो या नगरीय, धनी हो या निर्धन परिवार सभी समुदायों की एक सार्वभौमिक विशेशता है। इसके बाद भी विभिन्न समुदायों में परिवार की प्रकृति समान नही होती। परम्परागत और कृशि प्रधान समाजों में अनेक पीढियों के लोग साथ-साथ रहकर बड़े परिवारों की स्थापना करते हैं। इन्हें हम संयुक्त अथवा विस्तृत परिवार कहते हैं। आधुनिक, जटिल और बड़े समाजों में परिवार का आकार तुलनात्मक रूप से बहुत छोटा होता है। प्राय: एक परिवार में केवल पति पत्नी और अनेक अविवाहित बच्चे ही रहते हैं। ऐसे परिवारों को मूल परिवार अथवा एकाकी परिवार कहा जाता है।"2

परिवार से बालक को संस्कार प्राप्त होते हैं। यह संस्कार उसे भावी जीवन में एक मार्गदर्शक के रूप में उचित अनुचित का बोध कराते हैं। परिवार में बालक अपने माता-पिता के अनुभवों के आधार पर जीवन के सही मार्ग पर आगे बढने की प्रेरणा को प्राप्त करता है। परिवार सामाजिक नियन्त्रण के अनोपचारिक साधन के रूप में बालक को नियन्त्रित करता है ताकि वह कभी भी गलत या बुराई के मार्ग पर न चल सके। परिवार के द्वारा बालक समाज में अनुकूलन, सहयोग और सामंजस्य करना भी सीखता है।

परिवार प्रत्येक व्यक्ति के जीवन में उसके जीवन का केन्द्रबिन्दु होता है। मनुश्य का जीवन प्रमुख रूप से अपने परिवार के इर्द गिर्द घूमता है। परिवार वह स्थान है जहां वह स्वयं को अपनी प्रस्थिति के अनुरूप निर्धारित भूमिका का निर्वहन करना सीखता है। परिवार में व्यक्ति में एकता की भावना का विकास होता है तथा परिवार में व्यक्ति अपनी कमियों को जानकर उन्हें दूर करने का प्रयास करता है। इस प्रकार उसमें संगठित जीवन जीने की भावना का विकास होता है। परिवार में व्यक्ति का षारीरिक, मानसिक, सामाजिक, नैतिक, चारित्रिक विकास होता है, उसमें अपने जीवन को आदर्शों, मूल्यों एंव संस्कारों के अनुरूप जीने की भावना का विकास होता है। 
परिवार मे सभी सदस्य एक दूसरे के सुख-दुख का ध्यान रखते हैं तथा सहिश्णुता, त्याग, उत्तरदायित्व की भावना प्रमुख रूप से बालक परिवार से ही सीखता है। तथा सभी लोग एक साथ मिलकर तीज त्यौहार, विवाह तथा अन्य उत्सवों पर सम्मिलित होते हैं इस प्रकार बालक में प्रेम की सुदुढ़ भावना का विकास होता है तथा वह अपनी संस्कृति, परम्पराओं एंव रीतिं रिवाजों को सीखता है।

परिवार एक उपयोगी और प्रभावशाली साधन के रूप में बालक में उचित अनुचित का अन्तर स्पश्ट करने का बोध विकसित करता है। उसमें नैतिक गुणों का विकास करता है। परिवार में व्यक्ति को मानसिक सन्तोश, मनोवैज्ञानिक सुरक्षा आदि का प्रमुख रूप से वातावरण मिलता है। कहानियों एंव उदाहरणों के माध्यम से बालक में चरित्र निर्माण कल्पनाशीलता, नैतिक गुणों, संस्कृति, संस्कार, आदर्शों मूल्यों आदि का विकास किया जाता है। बालक अपनी जिज्ञासाओं के बारे में पूछता है तथा उनके अनुभवों से ज्ञानवर्धक जानकारी प्राप्त करता है। बडों का प्रेम आशीर्वाद उसे आगे बढने के लिए मनोवैज्ञानिक रूप से प्रेरित करने का कार्य भी करते हैं। परिवार से वह दूसरों का सम्मान करना भी सीखता है उसे पारस्परिक कर्तव्यों का भी बोध होता है। परिवार वह स्थान है जहॉ सदस्यों में संगठन एंव एकता का विकास होता है। यदि समाज में परिवारों में संगठन होता है तो समाज में भी निश्चित रूप से संगठन की भावना का विकास होता है। इस प्रकार परिवार सामाजिक संगठन के आधार के रूप में एक सशक्त माध्यम के रूप में कार्य करता है।

परिवार से बालक में मानवतावादी धर्म का भी विकास होता है उसमें दूसरों की सहायता करने की भावना भी विकसित होती है। परिवार शिक्षा के अनौपचारिक साधन के रूप में कार्य करता है। इस प्रकार परिवार बालक के समाजीकरण के अभिकरण के रूप में प्रमुख स्थान रखता है। परिवार में व्यक्ति संस्कृति के आदर्शों मूल्यों को देखता सीखता है तथा आत्मसात करता है। वर्तमान निरन्तर परिवर्तित एंव गतिशील परिवेश में परिवार निम्नलिखित रूप में समाजीकरण के एक सशक्त साधन के रूप में अपनी भूमिका को और अधिक सफलतापूर्वक रूप में निभा सकता है :-

1. बालकों के समक्ष नि:स्वार्थ प्रेम की भावना का आदर्श रखा जाये।

2. परिवार में उत्तम आदर्शों को प्रस्तुत किया जाये।

3. माता-पिता किसी भी प्रकार के लड़ाई झगडे न करें, ताकि बालक के मन पर कोई दुश्प्रभाव न पड़े, क्योंकि बाल मन कच्ची मिट्टी के समान होता है। वह जो देखता सुनता है उसी को तुरन्त आत्मसात करता है।

4. प्रेम, त्याग, सहयोग, सामन्जस्य की भावना, परिवार के सदस्यों में बढ़ाई जाये।

5. बच्चों को महापुरूशों की प्रेरक कहानियां सुनाई जायें।

6. परिवार में बालक में स्वस्थ मानसिकता का विकास किया जाये।

7. परिवार में किसी भी रूप में कलह का वातावरण न उत्पन्न होने दिया जाये।

8. माता-पिता अपने बच्चो के साथ समय व्यतीत करें उनकी बातों को सुनें एंव समझें। उनके प्रश्नों के उत्तर दें। उनकी जिज्ञासाओं का समाधान करें।

9. उनमें उचित अनुचित का अन्तर स्पश्ट करें।

10. उन्हें निडर एंव साहसी बनायें।

11. लड़का एंव लड़की में किसी प्रकार का भेद भाव न करें।

12. परिवार में रत्री एवं पुरूश सभी के विचारों को समान महत्व दिया जाये ताकि बालक के मन पर अनुकूल प्रभाव पड़े।

13. बच्चों की बातों को सुना एंव समझा जाय।

14. परिवार में बच्चों के साथ मित्रवत व्यवहार किया जाये। ताकि बालक अपने मन की बात अपने माता पिता को निडर होकर बता सकें।
15. परिश्रम के महत्व को समझाया जाये।

16. भावी जीवन के लिए उनमें सकारात्मक दृश्टिकोण को विकसित किया जाये।

17. घरेलू कार्यों में भी उनको सम्मिलित करें, ताकि वह उन कार्यों को भी सीख सके।

18. बात-बात पर बच्चों को डांटना नहीं चाहिए।

19. बच्चों से विभिन्न सामाजिक विशयों पर बातचीत करें।

20. उनमें उत्तरदायित्व की भावना को विकसित करने का कार्य किया जाये।

21. बच्चों की बेवजह की जिद पूरी न की जाये।

22. बच्चों में मितव्ययिता की भावना का विकास किया जाये।

23. उनको उत्तम व्यवहार के महत्व को बताया जाये।

24. स्वावलम्बी या आत्म निर्भर होने के महत्व को समझा जाए।

25. संस्कृति की जानकारी दी जाये।

26. उनमें तार्किक दृश्टिकोण विकसित किया जाये। उनको रचनात्मकता, कौशल विकास, स्वस्थ मनोरंजन के विशय में बताया जाये।

27. उनमें अतिथि सत्कार की भावना विकसित की जाये।

28. विचारों की अभिव्यक्ति की स्वतन्त्रता दी जाये।

29. मनोवैज्ञानिक सुरक्षापूर्ण वातावरण उपलब्ध हो।

30. उनको शिक्षा एंव पठन पाठन की उपयोगिता बतायी जाये एंव उनका बौद्धिक विकास किया जाये।

31. बालकों में पर्यावरण के प्रति उत्तरदायित्व की भावना विकसित की जाये।

32. इस प्रकार परिवार स्वस्थ समाजीकरण के सशक्त अभिकरण के रूप में अपनी महत्वपूर्ण भूमिका निभाने में अधिक प्रभावी हो सकता है।

\section{संन्दर्भ ग्रन्थ:-}

1. समाजशास्त्र, पृश्ठ संख्या-157 हिरेन्द्र प्रताप सिंह, नवीन कुमार।

2. समाजशास्त्र, पृश्ठ संख्या-157 डा0 गोपाल कृश्ण अग्रवाल। 